\title{
Pengaruh Pendidikan Kewirausahaan Terhadap Minat Berwirausaha
}

\author{
Glisina Dwinoor Rembulan ${ }^{1}$ \\ Universitas Bunda Mulia \\ Email: grembulan@bundamulia.ac.id \\ Fabianus Fensi ${ }^{2}$ \\ Universitas Bunda Mulia \\ Email: ffensi@gmail.com
}

\begin{abstract}
Central Bureau of Statistics (BPS) explained that from 2010-2013 Micro Small and Medium Enterprises (MSMEs) in Indonesia has increased. This explains that interest in entrepreneurship in Indonesia still become a trend that gets attention for the people of Indonesia. The government's concern in the field of entrepreneurship is increasingly directed in various business actors, one of them is the young generation. This is in accordance with the government program in 2017 where the launch of Beginner Entrepreneurship (WP). This explains that the opportunity to start a business at a young age is no longer an obstacle in view of the support from the government that participated in encouraging the new WP in Indonesia. Educational institutions can be a training place for entrepreneurship incubation for students. Encouragement through the role of courses in the institution should be able to walk in harmony. Readiness of students is not uncommon to be a barrier to start a business. This study aims to explain whether there is an influence between the factors of encouragement of educational institutions and entrepreneurship courses to entrepreneurial interests for students. By using SPSS and error rates of 5\%, this results that both the educational institution and the role of entrepreneurship courses partially affect student entrepreneurship interests. This study has limitation on the use of sample quantities and independent variables that still tend to be within a small range. Therefore, next researches may consider this as input.
\end{abstract}

Keywords: encouragement, institution, education, intention, entrepreneur

ABSTRAK: Badan Pusat Statistik (BPS) menjelaskan bahwa dari tahun 2010-2013 Usaha Mikro Kecil dan Menengah (UMKM) di Indonesia mengalami peningkatan. Data tersebut dapat menjelaskan gambaran bahwa minat berwirausaha di Indonesia masih menjadi tren yang mendapat perhatian bagi masyarakat Indonesia. Kepedulian pemerintah dalam bidang kewirausahaan semakin terarah di berbagai lapisan pelaku usaha, salah satunya adalah generasi muda. Hal ini sesuai dengan program pemerintah tahun 2017 dimana mencanangkan Wirausaha Pemula (WP). Hal ini menjelaskan bahwa peluang untuk memulai usaha di usia muda bukan lagi menjadi hambatan melihat dukungan dari pemerintah yang ikut serta mendorong lahirnya WP baru di Indonesia. Institusi pendidikan dapat menjadi pelatihan tempat inkubasi kewirausahaan bagi para mahasiswa. Dorongan melalui peran mata kuliah yang ada di institusi sudah seharusnya dapat berjalan selaras. Kesiapan mahasiswa tidak jarang menjadi hambatan tersendiri untuk memulai usaha. Penelitian ini bertujuan untuk menjelaskan apakah terdapat pengaruh antara faktor dorongan institusi pendidikan dan mata kuliah kewirausahaan terhadap minat berwirausaha bagi para mahasiswa. Dengan menggunakan SPSS dan angka galat sebesar 5\%, hasil ini menjelaskan bahwa baik dorongan institusi pendidikan dan peranan mata kuliah kewirausahaan secara parsial memengaruhi minat berwirausaha mahasiswa. Penelitian ini memiliki keterbatasan pada penggunaan jumlah sampel dan peubah bebas yang masih cenderung berada dalam cakupan kecil. Oleh karena itu, penelitian berikutnya dapat mempertimbangkan hal ini sebagai pengembangan penelitian selanjutnya.

Kata Kunci: dukungan, institusi, pendidikan, minat, wirausaha

\section{PENDAHULUAN}

Publikasi data Badan Pusat Statistik (BPS) menjelaskan bahwa dari tahun 20102013 Usaha Mikro Kecil dan Menengah (UMKM) di Indonesia mengalami peningkatan dari kuantitas (https://www.bps.go.id, 2016). Data tersebut dapat menjelaskan gambaran bahwa minat berwirausaha di Indonesia masih menjadi tren yang mendapat perhatian bagi masyarakat Indonesia. Untuk terus meningkatkan jumlah wirausahawan, tahun 2013 pemerintah membuat program Gerakan Kewirausahaan Nasional (GKN) yang hingga tahun 2016 berhasil melahirkan 193 ribu wirausaha yang bergerak di beragam sektor usaha (http://www.depkop.go.id, 2016 ). 


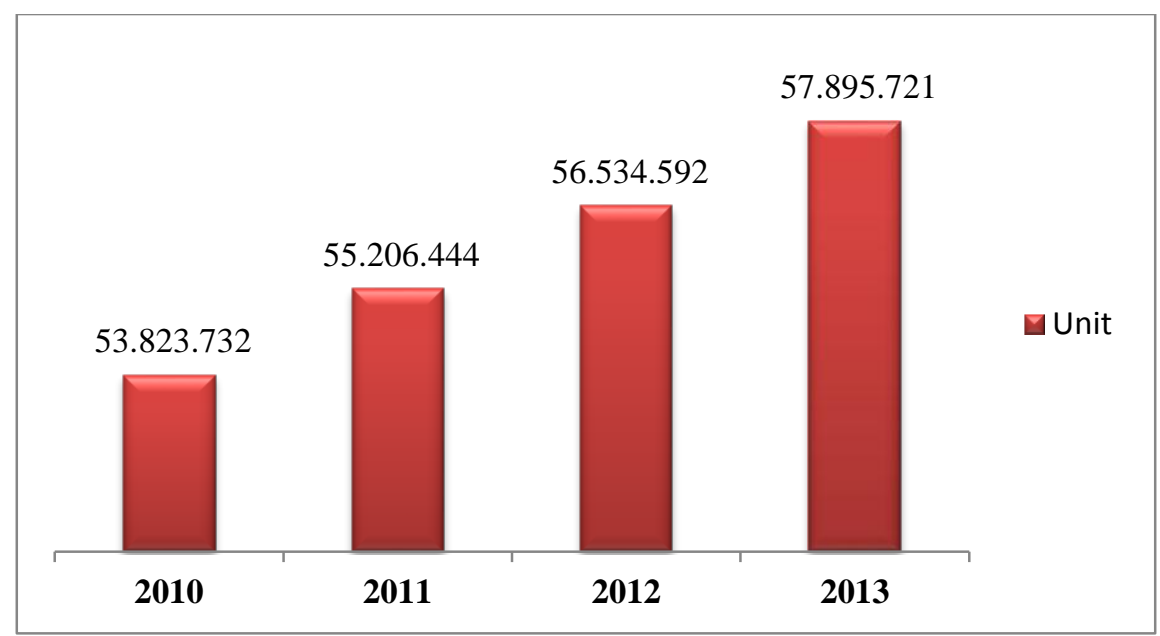

\section{Gambar 1. Jumlah Usaha Mikro Kecil \& Menengah (UMKM) di Indonesia Tahun 2010-2013}

Sumber: https://www.bps.go.id (2016)

Kepedulian pemerintah dalam bidang kewirausahaan semakin terarah di berbagai lapisan pelaku usaha, salah satunya adalah generasi muda. Hal ini sesuai dengan program pemerintah tahun 2017 dimana mencanangkan Wirausaha Pemula (WP) untuk target 10 ribu WP dengan serapan anggaran sebesar Rp. 100 miliar (http://www.depkop.go.id, 2016 ). Hal ini menjelaskan bahwa peluang untuk memulai usaha di usia muda bukan lagi menjadi hambatan melihat dukungan dari pemerintah yang ikut serta mendorong lahirnya WP baru di Indonesia. Hisrich, Peters, \& Shepherd (2010, hal. 40) menjelaskan bahwa individu dapat memulai untuk berwirausaha pada usia 22 tahun. Rentang usia tersebut dapat ditemui di jenjang perkuliahan. Informasi dan pengetahuan mengenai kewirausahaan diperoleh pada mata kuliah kewirausahaan ataupun mata kuliah terkait lainnya seperti business star-up, business plan, perilaku organisasi dan sebagainya.

Institusi pendidikan dapat menjadi pelatihan tempat inkubasi kewirausahaan bagi para mahasiswa (Nastiti, Indarti, \& Rostiani, 2010) yang memiliki ketertarikan dalam bidang kewirausahaan. Bentuk inkubasi dapat dimulai dari skala yang sangat kecil seperti pembuatan rencana bisnis sampai kepada membuat rencana pemasaran yang sederhana. Institusi melalui rancangan mata kuliah secara tidak langsung ikut mendorong mahasiswa untuk melanjutkan ke tahapan realisasi usaha (Sahban, Ramalu, \& Syhputra, 2016) atau paling tidak sudah mengenal dasar kewirausahaan, rancangan konsep berwirusaha, hingga strategi mengatasi hambatan dan permasalahan yang ada dalam menjalankan kewirausahaan. (Draycott \& Rae, 2011)

Dorongan melalui peran mata kuliah yang ada di institusi sudah seharusnya dapat berjalan selaras. Kesiapan mahasiswa tidak jarang menjadi hambatan tersendiri untuk memulai usaha (Arrighetti, Fabio, \& Lasagni, 2014). Berbagai faktor terkait pengetahuan sebagai dampak pada mata kuliah kewirsahaan memang bisa saja bermunculan, seperti kemampuan untuk menangkap peluang pasar (Draycott \& Rae, 2011) atau bahkan pertimbangan risiko untuk berwirausaha (Elmansori, 2014) yang masih mendominasi keputusan. Oleh karena itu, sebagai dentifikasi masalah dalam penelitian ini adalah masih diperlukan kajian untuk mengukur kembali peranan dukungan institusi khususnya pada mata kuliah yang ada dalam mendorong mahasiswa untuk berwirausaha. Hal ini didasarkan juga pada temuan bahwa paling tidak terdapat 55 penelitian yang sudah melakukan kajian mengenai konsep kewirausahaan (Lubis, 2015).

\section{Tujuan dan Manfaat Penelitian}

Tujuan penelitian ini adalah untuk mengetahui apakah terdapat pengaruh dukungan insitusi melalui mata kuliah kewirausahaan yang diberikan dengan minat mahasiswa untuk berwirausaha. Manfaat penelitian ini diharapkan dapat menjadi bahan pengembangan dan tambahan bagi kajiankajian teoritis mengenai konsep kewirausahaan 
khususnya pada generasi muda yang dimulai dari mahasiswa. Sebagai manfaat secara manajerial, penelitian ini diharapkan mampu memberikan masukan dan pertimbangan mengenai latar belakang pengetahuan dan wawasan yang terkait dengan konsep dasar kewirausahaan yang diberikan oleh tiap institusi pendidikan yang ada. Hal ini akan bermanfaat secara tidak langsung untuk memberikan pertimbangan kepada mahasiswa mengenai manfaat dari mata kuliah kewirausahaan yang dapat digunakan sebagai dasar untuk berwirausaha.

\section{TINJAUAN PUSTAKA}

\section{Dukungan Insitusi Pada Kewirausahaan}

Inovasi dapat dipengaruhi oleh karakter suatu negara dan kondisi pasar yang ada (Bessant \& Tidd, 2011, hal. 94). Lebih lanjut dijelaskan bahwa negara memberikan pengaruh pada 3 faktor yaitu kompetensi (pendidikan, penelitian), mekanisme perekonomian suatu negara (permintaan pasar, harga pasar, dan persaingan), dan institusi (metode pendanaan, pengawasan, dan pengaturan usaha). Inovasi dalam hal ini dapat mendukung perekonomian suatu negara, seperti Korea Selatan yang saat ini menjadi negara paling inovatif (Setiawan , 2017). Tidak dipungkiri bahwa inovasi dapat mendukung sasaran pemerintah dalam pengembangan yang merata di kota maupun desa khususnya dalam menciptakan lapangan pekerjaan dan kesejahteraan dalam konteks kewirausahaan (Shal, Amar, Allahyari, \& Ramezani, 2016).

Pendidikan merupakan tempat yang berperan penting untuk membantu pelaku wirausaha untuk mempersiapkan diri dalam mengatasi masalah yang ada dalam menjalankan usaha (Hisrich, Peters, \& Shepherd, 2010). Hal ini juga menjelaskan bahwa insitusi sebagai tempat berlangsungnya proses belajar mengajar dapat menjadi tempat pembinaan dini yang sesuai dalam mendorong mahasiswa untuk berwirausaha. Pendidikan mengenai kewirausahaan di beberapa negara seperti di Amerika, Eropa, dan Canada sudah dimulai sejak tahun 1950an menyatakan bahwa Harvard Business Scholl (HBS) dan di Amerka Serikat sudah memulai program pendidikan berbasis kewirausahaan sejak tahun 1945 (Mwasalwiba, 2010). Di Inggis dan Irlandia, pendidikan berbasis kewirausahaan ini memiliki fokus pada perilaku berorganisasi, kemampuan dalam membangun bisnis dan memberdayakan sumber daya manusia (Draycott \& Rae, 2011). Dalam kaitannya dengan bentuk implementasi pendidikan berbasis kewirausahaan, kualitas pendidikan yang diberikan kepada mahasiswa merupakan mandat bagi tiap institusi pendidikan (Paje, 2016).

Nastiti, Indarti, \& Rostiani(2010) menjelaskan insitusi akademik seperti universitas sudah menjadi tempat pelaksanaan inkubasi yang bersifat kewirausahaan yang melibatkan mahasiswa. Tidak jarang ditemui di universitas-universitas di Indonesia yang telah melakukan hal demikian. Baik universitas negeri maupun swasta memiliki program tersendiri dengan salah satu tujuan utamanya adalah sebagai pendorong mahasiswa untuk berwirausaha baik sejak masih di perkuliahan maupun setelah menyelesaikan perkuliahan. Universitas turut berperan penting dalam memberikan penguasan informasi, pengetahuan dan wawasan mengenai kewirausahaan bagi para mahasiswa dalam bentuk pendidikan kewirausahaan. Hal ini secara tidak langsung menjelaskan bahwa universitas mendorong mahasiswa untuk menjai pencipta lapangan kerja (Sahban, Ramalu, \& Syhputra, 2016).

Di Indonesia, universitas seperti Institut Teknologi Bandung (ITB) dan Universitas Pendidikan Indonesia (UPI) memiliki program pendidikan berbasis kewirausahaan melalui bentuk inkubator bisnis dimana langsung melibatkan mahasiswa dalam melakukan kajian dan praktek pada ide bisnis usaha (Lubis, 2015). Langkah seperti ini dapat menjadi pendorong bagi mahasiswa untuk berwirausaha. Lebih lanjut bahwa pendidikan dapat memberikan perilaku yang positif dalam menjalankan kinerja usaha (Athina \& Papagiannis, 2013). Dalam konsep pendidikan berbasis kewirausahaan, mahasiswa diajarkan untuk lebih mengenal risiko, mampu mengendalikan faktor-faktor produksi yang dimiliki, dan dapat menentukan produk/jasa khususnya pada target potensial (Akarue \& Adogbeji, 2014).

\section{Wirausaha Muda}

Mengacu pada lanjutan program GKN yang digalakkan pemerintah, maka istilah wirausaha pemula dapat mewakili para mahasiswa yang memiliki ketertarikan pada 
industri kewirausahaan. Generasi muda di negara-negara berkembang menjadi pendukung pada kondisi perekonomian dan sosial suatu negara (Furstenberg Jr, 2010), khususnya dalam menghadapi globalisasi ekonomi yang semakin berkembang (Stromquist \& Monkman, 2014). Program penyediaan lapangan pekerjaan oleh pemerintah memiliki angka batasan penyerapan yang memungkinkan tidak tertampunya semua angkatan pencari kerja yang ada. Oleh karena itu kewirausahaan dinilai mampu menjadi salah satu solusi yang tepat untuk mengatasi permasalahan tersebut.

Wirusaha pemula yang merupakan generasi muda suatu negara adalah kelompok dengan demografi yang cepat berkembang sekarang ini (Alves, Cavenaghi, \& Martine, 2013) dan memiliki potensi yang besar dalam menangkap peluang pasar (Gonzales, 2011) yang dapat menciptakan lapangan pekerjaan. Seperti yang dijelaskan sebelumnya bahwa kelompok ini dapat memulai usaha pada rentang usia 22-45 tahun (Hisrich, Peters, \& Shepherd, 2010) yang merupakan usia produktif. Tren mahasiswa untuk berwirausaha menunjukkan angka yang cenderung menurun (Gelard \& Saleh, 2011). Pembahasan yang

\section{Peubah Operasional}

spesifik mengenai tren tersebut khususnya mengenai tindak kesiapan mahasiswa dalam berwirausaha telah dijelaskan oleh Arrighetti, Fabio, \& Lasagni (2014). Hisrich, Peters, \& Shepherd (2010) menjelaskan bahwa keputusan untuk berwirausaha menuntut untuk memiliki karakter yaitu berpikir efektuasi, mampu beradaptasi secara kognitif, dan selalu belajar dari kegagalan.

\section{Penelitian Sebelumnya}

Penelitian sejenis pernah dilakukan oleh Sipitanou \& Papagiannis (2013) yang menemukan bahwa pengajaran kewirausahaan melalui praktik di Yunani sangat penting untuk memperoleh keterampilan. Kemudian penelitian yang dilakukan oleh Elmansori (2014) di Yordania \& Uni Emirat Arab juga menjelaskan bahwa pendidikan kewirausahaan dalam bentuk inkubator bisnis menjadi syarat penting dalam mendukung layanan bisnis, inovasi, dan pengembangan kewirausahaan. Oleh karena itu, penelitian ini mencoba untuk mengukur pengaruh dukungan insitusti pendidikan (dorongan dan mata kuliah) terhadap minat berwirausaha mahasiswa.

Tabel 1. Peubah Operasional

\begin{tabular}{|c|c|}
\hline Dimensi/Indikator & Skala Pengukuran \\
\hline Dorongan institusi (motivasi) & \multirow{3}{*}{ Likert $1 \mathrm{~s} / \mathrm{d} 5$} \\
\hline $\begin{array}{l}\text { Pengetahuan yang didapat dari } \\
\text { mata kuliah }\end{array}$ & \\
\hline Metode penyampaian mata kuliah & \\
\hline Minat Berwirausaha & \\
\hline
\end{tabular}

\section{METODE PENELITIAN}

\section{Model \& Hopotesis}

Hipotesis penelitian yang digunakan dalam penelitian ini adalah sebagai berikut:

H1: Ada pengaruh dorongan institusi terhadap minat berwirausaha

$\mathrm{H} 2$ : Ada pengaruh dukungan mata kuliah kewirausahaan terhadap minat berwirausaha

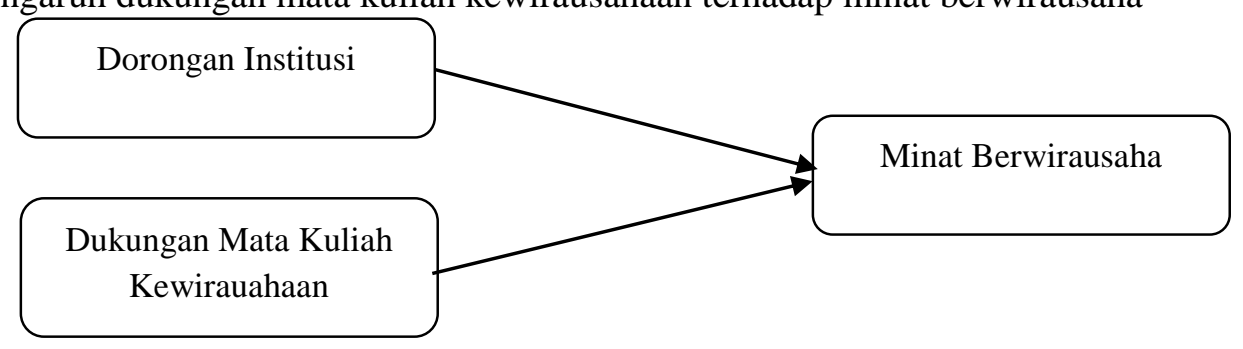

Gambar 2. Model Penelitian

Sumber: data primer 


\section{Pengumpulan Data}

Penelitian ini menggunakan kuesioner dengan menggunakan 30 responden (didasarkan pada teknik jumlah sampel yang dipopulerkan Hair dimana jumlah indikator dikali dengan 5). Jumlah ini juga sesuai dengan teknik yang dipopuler Roscoe dimana jumlah minimal sampel untuk populasi yang tidak diketahui adalah sebanyak 30 orang. Kuesioner menggunakan skala pengukuran Likert dengan rentang 1 sampai dengan 5 dimana angka 3 dinyatakan dengan netral. Kuesioner diberikan secara acak kepada mahasiswa dan juga lulusan yang sudah mendapatkan mata kuliah kewirausahaan pada Universitas X di Jakarta. Data kuesioner tersebut akan diolah dengan menggunakan SPSS.

\section{HASIL DAN PEMBAHASAN}

Tabel 2 menjelaskan bahwa seluruh item memiliki nilai yang sahih dengan melihat pada nilai yang terdapat pada corrected item-total correlation yang harus di atas 0,361 (nilai $r$ tabel). Sedangkan tabel 3 menjelaskan nilai kehandalan atau sebesar 0,826 .

Tabel 2. Kesahihan

\begin{tabular}{lll}
\hline Item & $\begin{array}{l}\text { Corrected Item } \\
\text { Total Correlation }\end{array}$ & Keterangan \\
\hline $\mathrm{X} 1$ & 0,719 & Sahih \\
\hline $\mathrm{X} 2 \mathrm{a}$ & 0,714 & Sahih \\
\hline $\mathrm{X} 2 \mathrm{a}$ & 0,739 & Sahih \\
\hline $\mathrm{X} 2 \mathrm{~b}$ & 0,777 & Sahih \\
\hline $\mathrm{X} 2 \mathrm{c}$ & 0,624 & Sahih \\
\hline $\mathrm{X} 2 \mathrm{~d}$ & 0,573 & Sahih \\
\hline $\mathrm{X} 2 \mathrm{e}$ & 0,558 & Sahih \\
\hline $\mathrm{X} 2 \mathrm{f}$ & 0,623 & Sahih \\
\hline $\mathrm{Ya}$ & 0,387 & Sahih \\
\hline $\mathrm{Yb}$ & 0,526 & Sahih \\
\hline $\mathrm{Yc}$ & 0,390 & Sahih \\
\hline
\end{tabular}

Sumber: diolah dengan SPSS 22, $(\mathrm{n}=30)$

Tabel 3. Kehandalan

Cronbach's

Alpha

0,826

Sumber: diolah dengan SPSS 22, $(\mathrm{n}=30)$

Uji normalitas ditampilkan pada gambar 3 yang menjelaskan hasil bahwa

data terdistribusi normal dilihat dari titiktitik yang ada menyebar di sekitar garis.

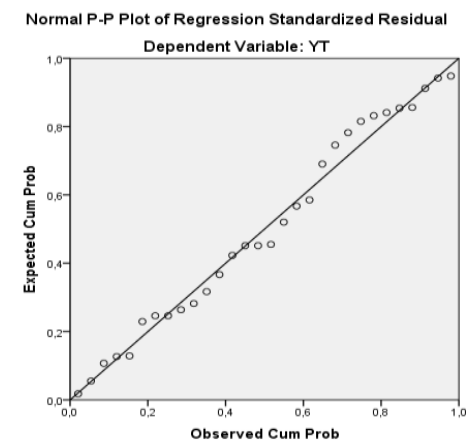

Gambar 3. Uji Normalitas

Sumber: diolah dengan SPSS 22, $(n=30)$ 
Uji Multikolinieritas diperlihatkan pada tabel 4 dimana dijelaskan bahwa tidak terjadi gejala multikolineritas karena nilai pada VIF tidak lebih dari nilai 10.

\section{Tabel 4 Uji Multikolinieritas}

\begin{tabular}{|c|c|}
\hline \multicolumn{2}{|c|}{ Collineartity Statistic } \\
\hline Tolerance & $V I F$ \\
\hline $\mathrm{X} 1$ & 2,169 \\
\hline $\mathrm{X} 2$ & 2,169 \\
\hline
\end{tabular}

Sumber: diolah dengan SPSS 22, $(n=30)$

Selanjutnya uji pada gambar 4 heteroskedastisitas karena dapat dilihat menjelaskan bahwa data pada penelitian ini tidak membentuk pola gelombang. tidak menunjukkan gejala

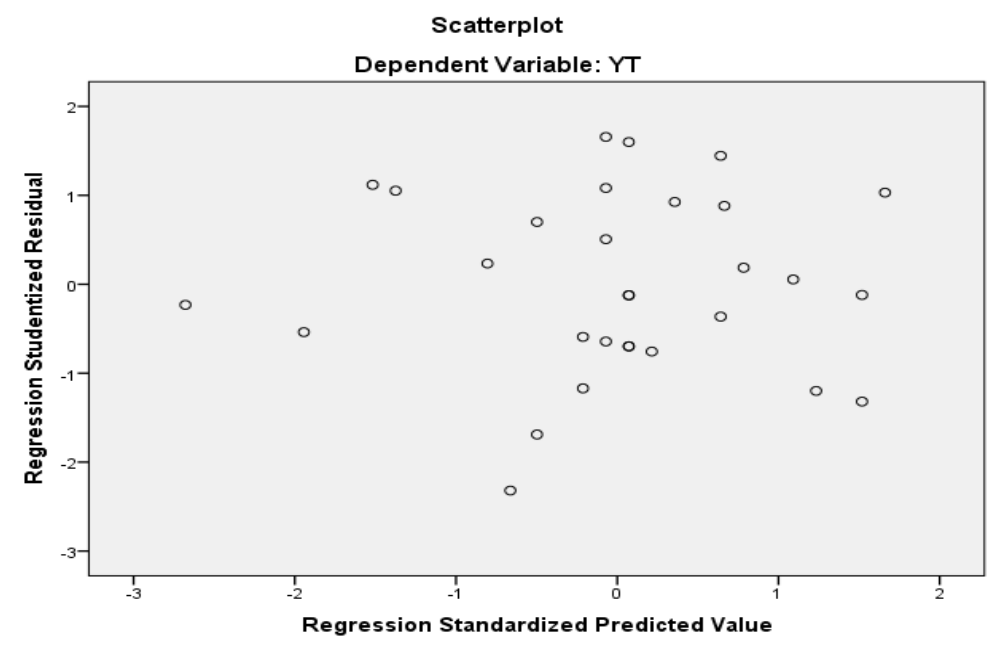

Gambar 3. Uji Normalitas

Sumber: diolah dengan SPSS 22, $(\mathrm{n}=30)$

Persamaan regresi pada model pada tabel 6 menjelaskan koefisien penelitian ini dapat dijelaskan dari tabel 5 dimana membentuk persamaan $\mathrm{Y}=7,406+$ 0,500X $1+0,097 \mathrm{X} 2+$ e. Selanjutnya nilai determinasi sebesar 0,073 atau sebesar 7,3 persen peubah X1 dapat dijelaskan dengan peubah X2.

\section{Tabel 5. Regresi}

\begin{tabular}{ll}
\hline \multicolumn{2}{l}{ Model } \\
\hline Constant & 7,406 \\
\hline $\mathrm{X} 1$ & 0,500 \\
\hline $\mathrm{X} 2$ & 0,097 \\
\hline
\end{tabular}

Sumber: diolah dengan SPSS 22, $(\mathrm{n}=30)$ 


$\begin{gathered}\text { Tabel } 6 \text {. Koefisien Determinasi } \\
\text { Model Summary }\end{gathered}$
\begin{tabular}{l}
$\boldsymbol{R} \quad$ Adjusted $\boldsymbol{R}$ Square \\
\hline $0,370 \quad 0,073$
\end{tabular}
Sumber: diolah dengan SPSS $22,(\mathrm{n}=30)$

Pengujian hipotesis dijelaskan dari tabel 7 dimana nilai pada sig untuk tiap peubahnya berada di atas 0,05 (galat $=5 \%$ ).
Dari hasil pengujian diperoleh bahwa Y dipengaruhi oleh X1 dan X2.

Tabel 7. Pengujian Hipotesis

\begin{tabular}{lc}
\hline Uji Hipotesis & sig \\
\hline Constant & 0,006 \\
\hline $\mathrm{X} 1$ & 0,465 \\
\hline $\mathrm{X} 2$ & 0,450 \\
\hline ber: diolah dengan SPSS $22,(\mathrm{n}=30)$
\end{tabular}

Dari hasil penelitian yang dilakukan, dorongan institusi perguruan tinggi dan dukungan mata kuliah kewirausahaan berpengaruh siginifikan terhadap minat mahasiswa untuk berwirausaha. Hal ini perlu ditindaklanjuti dengan membuat inkubator bisnis dalam sebuah perguruan tinggi agar ilmu yang sudah diterima dapat langsung diterapkan dalam dunia nyata.

\section{KESIMPULAN \& SARAN}

\section{Kesimpulan}

Berdasarkan hasil pengujian yang telah dilakukan maka kesimpulan dari penelitian ini adalah sebagai berikut:

1. Minat berwirausaha pada mahasiswa dipengaruhi oleh dorongan institusi pendidikan

2. Minat berwirausaha pada mahasiswa dipengaruhi oleh mata kuliah kewirausahaan yang disusun oleh institusi pendidikan
Sesuai dengan hasil penelitian ini juga, perlu dipertimbangkan kurikulum untuk mata kuliah kewirausahaan untuk diajarkan di semua program studi di institusi pendidikan agar terwujudnya wirausahawirausaha muda yang dapat menciptakan lapangan pekerjaan yang dapat bersaing dengan negara lain.

\section{Saran}

Sebagai saran pada penelitian ini adalah penelitian berikutnya dapat memperimbangkan untuk menggunakan faktor-faktor lain yang terkait dengan mata kuliah kewirausahaan dan dorongan institusi, seperti: pengaruh dosen praktisi di bidang kewirausahaan atau faktor praktik langsung berwirausaha. Penggunaan jumlah sampel yang lebih besar juga dapat mewakili karakter yang berbeda, misalnya mahasiswa yang berasal dari fakultas teknik atau bahasa. 


\section{DAFTAR ISI}

Ahmad, N. H., Ramayah, T., \& Tuan Muda, S. A. (2013). Unlocking The Entrepreneurial Propensity Among Prime-Age Malayasian: A MultiEthnic Analysis. ResearchersWorld Journal of Arts, Science \& Commerce, 4(1), 1-6.

Akarue, O. B., \& Adogbeji, V. (2014). Entrepreneurship Education as a Strategy For Enhancing Human Capital Development in Nigeria. Journal of Vocational and Technical Education, l(1).

Alves, J. E., Cavenaghi, S., \& Martine, G. (2013). Population and Changes in Gender Inequalities in Latin America. the XXVII CONFERENNCIA DA IUSSP. Busan.

Arrighetti, A., Fabio, L., \& Lasagni, A. (2014). Intangible assets and firm heterogeneity: Evidence from Italy. Research Policy, 43, 202-213.

Athina, S. A., \& Papagiannis, G. D. (2013). Education, Entrepreneuship and Entrepreneurial Activation: A Challenge for All. International Journal of Arts \& Sciences, 6(2), 139149.

Bessant, J., \& Tidd, J. (2011). Innovation and Entrepreneurship (2nd ed.). West Sussex: John Wiley \& Sons Ltd.

Draycott, M., \& Rae, D. (2011). Enterprise education in schools and the role of competency frameworks. International Journal of Entrepreneurial Behaviour \& Research, 17(2), 127-145.

Elmansori, E. (2014). Business Incubators in the Arab World. World Journal of Science, Technology and Sustainable Development, 11(4), 282-293.
Enu, D. B. (2012). Enhancing The Entrepreneurship Education in Nigeria. American Journal of Social Issues \& Humanities, 2(4), 232-239.

Furstenberg Jr, F. F. (2010). On a New Schedule: Transitions to Adulthood and Family Change. The Future of Children, 20 (1), 67-87.

Gelard, P., \& Saleh, K. (2011). Impact of some contextual factors on entrepreneurial intention of university students. African Journal of Business Management, 5(26), 10707-10717.

Gibb, A. (2011). Concepts into practice: Meeting the challenge of development of entrepreneurship educators around an innovative paradigm, The case of the International Entrepreneurship Educators' Programme (IEEP). International Journal of Entrepreneurial Behaviour \& Research, 2, 146-165.

Gonzales, R. G. (2011). Learning to be illegal undocumented youth and shifting legal contexts in the transition to adulthood. American Sociological Review, 76(4), 602-619.

Hisrich, R. D., Peters, M. P., \& Shepherd, D. A. (2010). Entreprenuership (8th ed.). Singapore: McGraw-Hill/Irwin.

http://www.depkop.go.id. (2016 , Agustus Senin ). Retrieved Juli Kamis , 2017 , from http://www.depkop.go.id: http://www.depkop.go.id/content/read/ 2017-program-wirausaha-pemulabakal-kembali-digulirkan/

https://www.bps.go.id. (2016, Desember Sabtu ). Retrieved Juli 6, 2017 , from https://www.bps.go.id: https://www.bps.go.id/index.php/linkT abelStatis/1322 
Lubis, R. L. (2015). The "Triple-I" Learning Model of Entrepreneurship Education in Indonesia: Where Do We Go From Here? International Journal of Arts \& Sciences, 8(7), 233-264.

Moi , T., Adeline , Y. L., \& Dyana , M. L. (2011). Young Adults Responses to Entrepreneurial Intent. Reaserchers World-Journal of Arts, Science \& Commerce, II(3), 37-52.

Money, U. (2016). The Creation and Development of Job in Nigeria: Entrepreneurship Enlightment. Researchers World - Journal of Arts, Science \& Commerce, 3(1), 96-100.

Money, U., \& Odibo, E. E. (2012). Application of Discrete Potential Theory for Human Capital Movement in The Nigeria Oil Industry. Journal of Finance and Banking Review, 6(1\&2).

Mwasalwiba, E. S. (2010). Entrepreneurship Education: A Review of Its Objectives, Teaching Methods, And Impact Indicators. Education + Training, 52(1), 20-47.

Nastiti, T., Indarti, N., \& Rostiani, R. (2010). Minat Berwirausaha Mahasiswa Indonesia dan Cina. Manajemen \& Bisnis, 9(2), 188-189.

Paje, M. J. (2016). Effectiveness of Set in Enhancing The Entrepreneurial Competencies of The Students Belonging to Special Population. International Journal of Arts \& Sciences, 9(3), 9-26.

Raimi, L., \& Towobola, W. L. (2011). Open Distance Learning (ODL): A Catalyst for Educational and Entrepreneurship
Development in Nigeria. Continental Journal of Education Research, 4(3), 1-11.

Sahban, M. A., Ramalu, S. S., \& Syhputra, R. (2016). The influence of social support on entrepreneurial inclination among business students in Indonesia. Information Management Business Review, 8(3), 32-46.

Saxena, S. (2012). Problems Faced by Rural Entrepreneurs and Remedies to Solve It. Journal of Business and Management, 3(1), 23-29.

Setiawan , S. R. (2017, Januari Rabu). http://ekonomi.kompas.com. Retrieved Juni Kamis, 2017 , from http://ekonomi.kompas.com: http://ekonomi.kompas.com/read/2017 /01/18/080200326/korea.selatan.negar a.paling.inovatif.di.dunia

Shal, F. K., Amar, T., Allahyari, M. S., \& Ramezani, B. (2016). Socio-economic Factors Affecting Spatial Planning of Entrepreneurship in Rural Area (Evidence from Masal County, Iran). Journal of Current Research in Science, 4(1), 40-46.

Sipitanou, A. A., \& Papagiannis, G. D. (2013). Education, Entrepreneurship and Entrepreneurial Activation: A Challenge for All. International Journal of Arts \& Sciences, 6(2), 139149.

Stromquist, N. P., \& Monkman, K. (2014). Globalization and Education: Integration and Contestation Across Cultures. R\&L Education. 